\title{
A gênese do mercado nacional e a Cia. Industrial Sanjoanense (c.1890-c.1913)
}

\author{
Afonso de Alencastro Graça Filho ${ }^{1}$
}

\begin{abstract}
Resumo: Esse artigo tem como objetivo discutir o conceito de mercado nacional por meio de informações de e mpresas fabris e comerciais publicadas pela Companhia Lloyd's, em 1913. Essas informações nos possibilitam considerar que a integração dos mercados regionais já havia se estabelecido durante o final do século XIX, convivendo com a escravidão e o crescimento dos núcleos urbanos. A Companhia Industrial São Joanense vai se caracterizar pelas condições regionais assimétricas que a construção do mercado nacional criou, concentrando o mercado de capitais no Rio de Janeiro e São Paulo.
\end{abstract}

Palavras-chave: Companhia Industrial São Joanense; mercado nacional; indústria têxtil no Brasil; mercado interno; desequilíbrios regionais no Brasil.

\section{La génesis del mercado nacional y Cia. Industrial Sanjoanense (c.1890-c.1913)}

Resumen: Este artículo tiene como objetivo debatir el concepto de mercado nacional a través de información de empresas industriales y comerciales publicada por Lloyd's Company en 1913. Esta información permite considerar que la integración de los mercados regionales ya se había establecido a fines del siglo XIX, conviviendo con la esclavitud y el crecimiento de los centros urbanos. La Compañía Industrial São Joanense se caracterizará por las condiciones regionales asimétricas que generó la construcción del mercado nacional, concentrando el mercado de capitales en Rio de Janeiro y São Paulo. Palabras clave: Compañía Industrial São Joanense; Mercado nacional; industria textil en Brasil; mercado interno; desequilibrios regionales en Brasil.

\section{The genesis of the national market and Cia. Industrial Sanjoanense (c.1890-c.1913)}

Abstract: This article aims to debate the concept of the national market through information from industrial and commercial companies published by the Lloyd's Company in 1913. This information allows us to consider that the integration of regional markets had already been established during the late 19th century, living with slavery and the growth of urban centers. Company Industrial São Joanense will be characterized by the asymmetric regional conditions that the construction of the national market created, concentrating the capital market in Rio de Janeiro and São Paulo.

Keyword: Company Industrial São Joanense; National market; textile industry in Brazil; intern market; regional imbalances in Brazil.

\section{(c) $(\mathrm{P})($}

DOI: https://doi.org/10.26512/patryter.v4i7.35060

Como citar este artigo: Graça Filho, A. A. (2021). A gênese do mercado nacional e a Cia. Industrial Sanjoanense (c.1890-c.1913). PatryTer - Revista Latinoamericana e Caribenha de Geografia e Humanidades, 4 (7), 1-11. DOI: https://doi.org/10.26512/patryter.v4i7.35060

Recebido: 10 de setembro de 2020. Aceite: 01 de novembro de 2020. Publicado: 01 de março de 2021. 1 Professor Titular de História do Brasil da Universidade Federal de São João del Rei, UFSJ. ORCID: https://orcid.org/0000-0001-8821-3024. E-mail: alencastrog@uol.com.br 


\section{Introdução: Revisando a constituição do mercado nacional pelas informações da Companhia Lloyd's}

Para essa reflexão trazemos o mapeamento nacional de grandes empresas e negócios por uma publicação excepcional em seus detalhes e fotografias, abrangendo todos os estados brasileiros. Essa obra foi realizada pela Companhia Lloyd's, em 1913. Essa firma inglesa de grande porte, dedicada aos seguros marítimos, também estava presente em vários estados brasileiros por meio de agências que representavam seus interesses.

A publicação declara seu objetivo de auxiliar os investidores sobre as condições brasileiras em diversos ramos de negócios, fornecendo um pequeno histórico das suas principais companhias e casas comerciais. Isso nos permitiu o uso de referências sobre a área de atuação de fábricas e empresas diversas. Podemos visualizá-las na dimensão geográfica de suas transações para 336 empresas dos estados do Pará, Amazonas, Bahia, Maranhão, Pernambuco, Ceará, Sergipe, Alagoas, Rio Grande do Norte, Minas Gerais, Rio de Janeiro, Rio Grande do Sul, Paraná, Santa Catarina e São Paulo, pertencentes ao setor de transformação e atuantes no Brasil no ano de 1913. Embora não se trate de um levantamento completo de todas as empresas do setor, mas selecionadas pela importância dos seus capitais. $\mathrm{O}$ âmbito geral de suas atuações comerciais em território nacional pode ser ilustrado no quadro 1.
Predominava a distribuição de manufaturados de forma nacional, abrangendo vários estados e as cidades mais importantes em termos populacionais. A ausência de informações sobre o item de atuação no mercado foi grande também, embora possamos colocar em dúvida se essas empresas, pelo volume de capital e produção, não atuaram além do mercado local ou regional. Respeitamos as informações prestadas na obra, porém, a comparação da produção entre as companhias têxteis que atuavam em amplitude nacional e aquelas sem informação, predominante para as sediadas no Rio de Janeiro, pode nos indicar que o número de empresas que colocavam suas mercadorias em vários estados da União, era bem maior do que as coletadas estritamente nas descrições fornecidas pela Lloyd's e apresentadas no quadro 2.

As companhias têxteis de São Paulo já apresentavam capitais superiores às demais congêneres dos outros estados, rivalizando com as empresas cariocas. A esfera de circulação de suas mercadorias é visivelmente nacional. As companhias têxteis do Rio de Janeiro lideravam as de maiores capitais, embora a publicação deixe de fazer menção à circunscrição de seus mercados na maioria das vezes, como comentamos. Também é curioso ver que fábricas em estados do Nordeste ou do Sul coloquem seus produtos em âmbito nacional, embora possuam algumas características particulares, de mesclarem a produção têxtil com investimentos agrícolas ou pecuários. Bem como, são em número menor.

Figura 1 - Companhia Industrial São Joanense

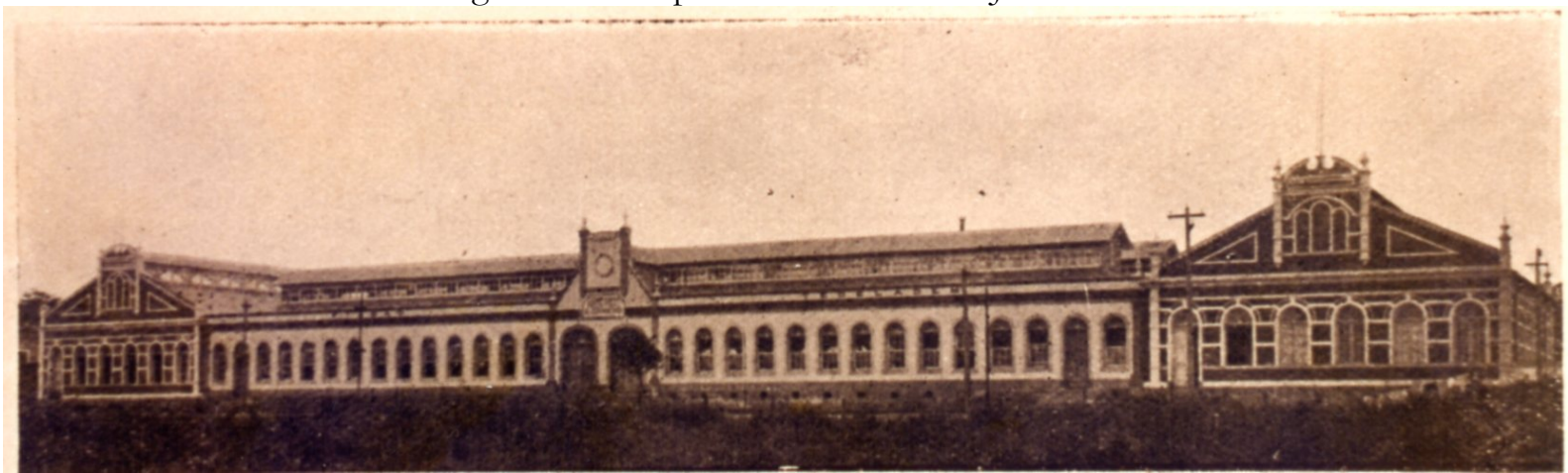

Fonte: Braga, T. (1913). Album da Cidadde de S. João D'El-Rei. Rio de Janeiro: Typ. Lithographia Pimenta de Mello \& Cia.

Quadro 1 - Atuação de 336 fábricas em território nacional, 1913

\begin{tabular}{|c|c|c|c|c|c|c|c|}
\hline \multicolumn{2}{|c|}{ Local } & \multicolumn{2}{c|}{ Regional } & \multicolumn{2}{c|}{ Nacional } & \multicolumn{2}{c|}{ S/Informação } \\
\hline 48 & $14,2 \%$ & 35 & $10,4 \%$ & 139 & $41,4 \%$ & 114 & $33,9 \%$ \\
\hline
\end{tabular}

Fonte: Lloyd, R. (1913). Impressões do Brazil no Seculo Vinte. Sua Historia, seo povo, commercio, industrias e recursos. Londres: Lloyd's Greater Britain Publishing Cia, Ltd. 
O caso da Companhia Industrial SãoJoanense, criada em 1891 com capitais originários particulares, de mesclarem a produção têxtil com da economia de abastecimento em Minas Gerais", revela um traço marcante dessa concorrência nacional no mercado interno. Quase todas as grandes companhias têxteis já utilizavam a produção de algodão nacional em 1913, seja a de seu estado em que estavam sediadas, como algumas paulistas ou nordestinas que plantavam seu próprio algodão, ou compravam o algodão em lã especialmente dos produtores nordestinos, que se tornaram os principais fornecedores dessa matériaprima, liquidando boa parte da importação de fios da Europa ou Estados Unidos. Essa integração da produção pelo uso do algodão nordestino alcança todos os estados, e a Cia. São-Joanense é uma dessas empresas que realizou a substituição dos fios importados por sua própria fabricação entre 1906 e 1908, adquirindo uma seção de fusos para a fiação e a matéria prima em Pernambuco, Bahia, Maceió, Paraná e na própria Minas Gerais. Vinte fábricas têxteis do país declararam que obtinham sua matéria-prima de fontes nacionais, a maioria de fornecedores nordestinos, o que representa $28 \%$ das 71 fábricas de tecidos listadas pela Lloyd's. Essa demanda do algodão em lã ou em fios é mais um elemento que incrementava a integração nacional dos mercados.

O mesmo acontecera com as construtoras e serrarias da cidade do Rio de Janeiro, dependentes das madeiras de Santa Catarina, Paraná e Rio Grande do Sul. As construtoras cariocas apresentavam um caráter nacional na prestação de seus serviços, atuando em obras no Sudeste e capitais do nordeste. Muitas companhias cariocas passaram a contratar representantes, chamados viajantes, ou criaram representações em outras cidades. $\mathrm{E}$ todas as fábricas têxteis do interior de São Paulo, Rio de Janeiro, Minas Gerais ou Nordeste se valem da proximidade com as vias férreas, construindo entroncamentos e extensões para o embarque de seus produtos. A Cia. São Joanense foi uma delas, que só se tornou uma realidade a partir da existência da Estrada de Ferro Oeste de Minas, inaugurada em 1881.

Se considerarmos que o mercado nacional estava em pleno desenvolvimento a partir do início do século XX, essa construção possui uma história e é a do desenvolvimento das ligações que articularam mercados regionais distantes por transporte de animais ou de cabotagem. O desenvolvimento das estradas de ferro na segunda metade do século XIX e a expansão do setor urbano industrial ao final do Oitocentos, nos parecem o ponto de partida dessa constituição do escoamento da grande produção têxtil ou de outras atividades fabris, bem como a do investimento de capitais, que transborda o nível local ou regional, atraindo investidores de todos os estados e estrangeiros, derivados da expansão capitalista de exportação dos bens de produção e a substituição de importações. No setor têxtil, no recenseamento de 1908, a produção nacional de tecidos foi avaliada em 130.000:000\$000 rs (equivalente a 8.211.666.667 libras), contra 24.558:665\$000 rs ii (1.551.289.006 libras) da importação desses manufaturados, equivalente somente a $19 \%$ da produção brasileira (Lloyd, 1913, p. 385).

Continuando com o modelo de Minas Gerais na produção têxtil, a partir da Cia. São Joanense, vemos que seu capital e maquinaria são bem inferiores às concorrentes do Rio e São Paulo. Bem possível que essa concentração do capital nas empresas da cidade do Rio de Janeiro explique a queda acentuada das exportações mineiras de panos rústicos para o mercado carioca, conforme dados de Roberto Martins, trabalhados por Libby (1996, pp. 274-275).

Quadro 2 - Atuação de 71 grandes companhias têxteis no Brasil

\begin{tabular}{|c|c|c|c|c|c|}
\hline \multirow{2}{*}{ Sede } & Local & Regional & Nacional & S/Informação & Total \\
\hline RJ & 1 & 1 & 2 & 20 & 24 \\
\hline SP & 3 & 3 & 8 & 6 & 20 \\
\hline MG & 0 & 1 & 2 & 4 & 6 \\
\hline PE & 1 & 0 & 2 & 3 & 4 \\
\hline BA & 0 & 1 & 0 & 3 & 4 \\
\hline RS & 0 & 0 & 3 & 0 & 2 \\
\hline SE & 0 & 0 & 4 & 2 & 71 \\
\hline Total & 5 & 0 & 0 & 39 & \\
\hline
\end{tabular}

Fonte: Lloyd, R. (1913). Impressões do Brazil no Seculo Vinte. Sua Historia, seo povo, commercio, industrias e recursos. Londres: Lloyd’s Greater Britain Publishing Cia, Ltd. 
As exportações da produção doméstica de panos de Minas em 1847-48 alcançara 2,6 milhões de metros e se mantivera nessa faixa durante cinco a seis anos seguintes, mas de 1868/69 não voltará a alcançar a faixa superior aos dois milhões de metros e em 1875-76, despenca abaixo do patamar de 1 milhão de metros até o final do século XIX. Da mesma forma, embora a fábrica São Joanense tenha resistido até aos nossos dias, a sua capacidade de concorrência com as grandes companhias têxteis deveria ser pequena, produzindo numa escala menor e com tradição nos tecidos aflanelados, um nicho de mercado.

Criada no Encilhamento (1891) i, a Cia. São Joanense começou sua atividade em São João del Rei em 1892, equipada com 40 teares e com capital inicial de 200:000\$000 rs. Ampliou suas instalações entre 1906 e 1908, criando as seções de fiação, com 1.614 fusos, e de tinturaria em 1906. Em 1913, contava com o capital de 300:000\$000 rs (equivalente a 19.937.500 libras), 78 teares e empregava 200 operários, com produção de fios e tecidos de algodão, cobertores e aflanelados, de 75.000 metros mensais (900 mil metros anuais). Para o escoamento da produção, um ramal da Estrada de Ferro Oeste de Minas adentrava o pátio da companhia trazendo o carregamento de lenha e matéria-prima. No retorno, os tecidos eram entregues à responsabilidade da estação ferroviária. Com o aumento da produção, utilizou-se também carroças com capacidade de carregarem até 20 fardos, cada fardo com 20 peças de 50 metros de tecidos. Os destinos dessas vendas eram os mercados do próprio estado, do Rio de Janeiro e São Paulo.

Comparando esses dados com as demais empresas têxteis, a primeira informação que podemos obter é que a Cia. São Joanense possuía o menor capital entre 45 companhias com seus capitais descritos na publicação da Lloyd's, de 1913. Todas elas haviam crescido seus capitais consideravelmente com a expansão do mercado de ações, na entrada do século XX. Nas outras dez companhias têxteis que apresentaram capitais inferiores ao patamar de 1.000:000\$000 rs (equivalente a 66.458 .333 libras), como a São Joanense, sete delas se dedicavam aos artigos de lã ou de malha, que empregavam um número inferior de operários e capital, a exemplo da Cia. Tijuca, no Rio, de tecidos de lã, fabricados com fios importados da Europa, com capital de 500:000\$000 rs em 1904 (ou 25.458.333 libras), ou a Cia. Paulista de Tecidos de Malha, com capital de 450:000\$000 rs em 1911 (ou 30.225.000 libras) (Lloyd, 1913, p. 422). Uma comparação com uma indústria têxtil do interior de São Paulo nos dá a amostra da pouca dinamicidade da Cia. São Joanense. A Cia. Taubaté Industrial, foi também criada no Encilhamento com o capital de 300:000\$000 rs (18.637.500 libras) , se dedicando a toalhas felpudas e brins. Em 1913, se preparava para ampliar seu capital para 2.000:000\$000 rs (132.916.666 libras), com o emprego de 1.016 teares, 33.000 fusos e 1.200 operários (Lloyd, 1913, p. 410, 418).

Figura 2 - Diretores, operários e crianças da Companhia Industrial São Joanense, no 01 maio de 1912

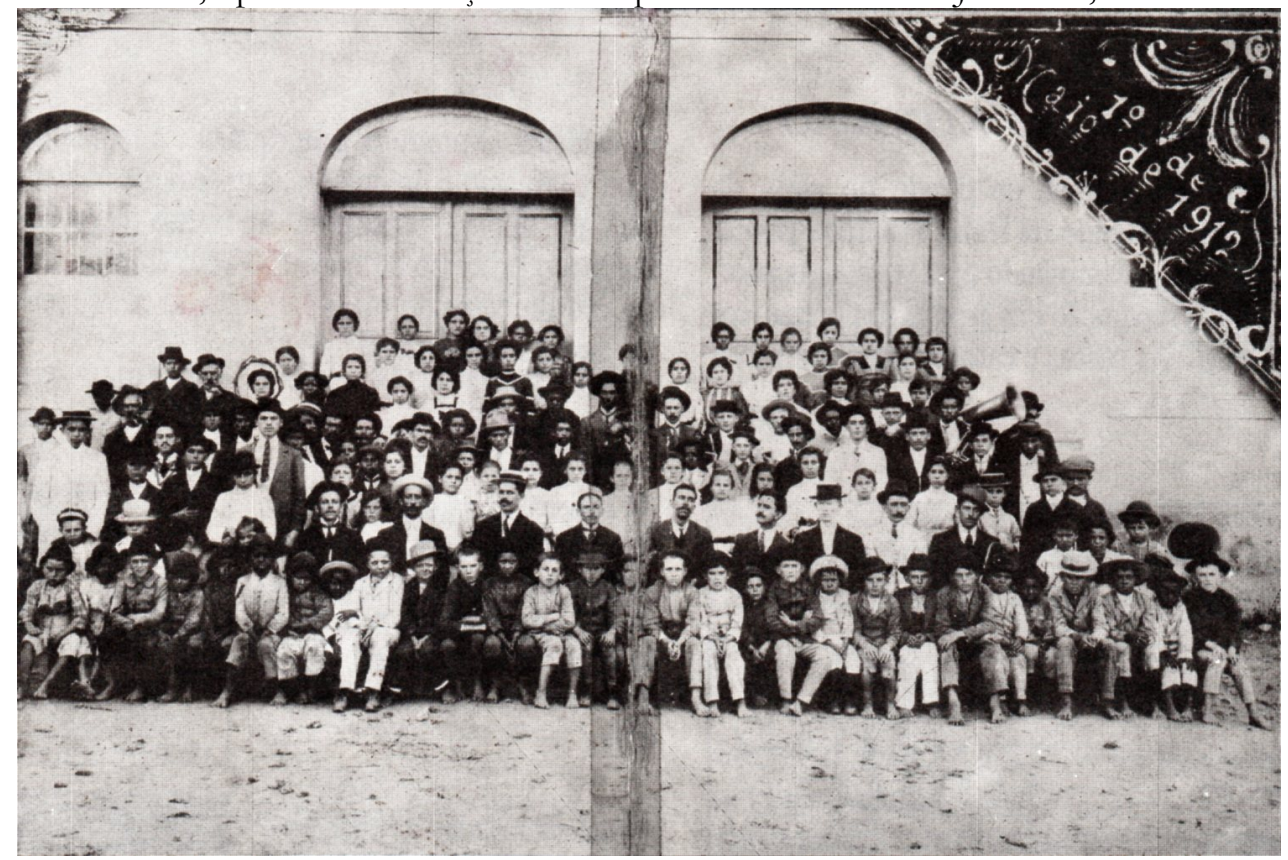

Fonte: Companhia Têxtil São Joanense. (1991). Folhetim comemorativo dos 100 anos da Companbia Têxtil São Joanense “Tecendo a história da Companbia Têxtil São Joanense, 1891-1991”, São João del Rei. 
Ou seja, alcançara o padrão das grandes têxteis do Rio e São Paulo. Mesmo outra companhia de porte médio como a Cia. São Joanense, a Cia. Fábrica de Tecidos D. Isabel, de Petrópolis, que iniciou suas atividades em 1889 com os recursos de 250:000\$000 rs (27.531.250 libras), crescera nominalmente seu capital em 1894 para 500:000\$000 rs (21.041.666 libras). Empregava mais do dobro de teares da São Joanense, 180 teares, 6.000 fusos e dava emprego a 350 pessoas. Sua produção diária era de 10.000 metros de brins variados, enquanto a São Joanense produzia cerca de 2.500 metros de riscados e aflanelados (Lloyd, p. 406, 409). Ambas empresas pareciam estacionadas em seus recursos no contexto de uma forte expansão dos investimentos no setor têxtil próximo ao limiar da Primeira Guerra Mundial.

Essa perda de dinamicidade da Cia. Industrial S. Joanense nos leva ao quadro mais geral dos desequilíbrios regionais do setor de transformação no país. Nos ateremos aos trabalhos de Cano (1985) e Gorender (1981), que ainda não comentamos e são remissões importantes para o tema, que tem sido pouco revisitado.

\section{As redes do mercado nacional e a historiografia brasileira}

Alguns autores consideraram que o surgimento do mercado nacional (ou mercado interno) só passou a existir com o resultado da extinção da escravidão e a expansão do consumo assalariado $^{\text {vi }}$. Outros caracterizaram o termo como sinônimo de mercado interno, localizando-o na criação do Estado Nacional, a partir da Independência vii. No entanto, compreendemos o mercado nacional como a integração dos mercados regionais, que formavam o mercado interno, como em Sereni (1980) ou Cerutti (1987). O termo também é dessa maneira aplicado por Cano (1985).

O processo de formação e integração do mercado nacional é compreendido na obra de Cano (1985) como sendo iniciado pela "afirmação da economia cafeeira do Brasil (1850) até a eclosão da "Crise de 1929". A "Crise de 1929" abriu o precedente de tornar o mercado nacional aberto à produção nacional e reforçava-se a competição capitalista inter-regional, nascida na década de 1920. A partir desse momento, a economia de São Paulo passava a promover a integração do mercado nacional. A conquista crescente do mercado nacional pela indústria paulista marcaria o nascimento do seu processo de integração.
Até cerca de 1929, as indústrias de grande porte puderam se instalar em regiões diversas do país, protegidas da competição nos seus mercados regionais pelas precárias vias de comunicação terrestres e pela cabotagem marítima (Cano, 1985, pp. 51-69).

A falta de integração do mercado nacional é assinalada por Cano (1985, p. 64) como resultante das grandes distâncias e do transporte deficiente, que eram fatores para a descentralização regional que beneficiava as maiores plantas industriais no século XIX até a "Crise de 1929". As localidades mais interiorizadas em relação ao litoral permitiram o surgimento de segmentos industriais com estrutura diversificada, formados por pequenas e médias indústrias. A razão para isso é que estavam duplamente protegidos pelos custos de transportes, tanto em relação aos produtos importados quanto aos de outras regiões do país. Mas esses segmentos tinham menor significação na produção industrial do país que os setores da grande indústria, caracterizada pelos têxteis ou da indústria de bebidas, fósforos, cimento, papel, cigarro e vidros.

$\mathrm{Na}$ dinâmica regional, Cano (1985) distingue a situação mais favorável à acumulação industrial em São Paulo do que para o restante do país. No Nordeste, pela alta concentração de terras, as plantas industriais têxteis e das usinas de açúcar adquiriram grandes dimensões. No Extremo-Sul, pela predominância da desconcentração da propriedade, implantou-se a pequena e média indústria. Em Minas Gerais, a estrutura agrária era marcada pela dispersão territorial e pela presença da pequena e média propriedade, o que dará margem à característica da indústria mineira, composta por pequenas e médias empresas. $\mathrm{Na}$ cidade do Rio de Janeiro a concentração industrial em grandes empresas foi gerada pela acumulação comercial e mercantil de capitais oriundos da cafeicultura do Vale do Paraiba, Minas Gerais e Espírito Santo. Mas é em São Paulo, onde a estrutura fundiária não conheceu os extremos das dimensões do latifúndio nordestino ou da pequena propriedade sulista, os padrões industriais obedeceram a eficiência exigida de porte adequado ao capital e tecnologia, seja nas grandes empresas ou nas médias e pequenas.

A cafeicultura paulista em expansão, contando com a política de estabilização cambial, pôde liberar seus excedentes para a diversificação de sua economia. O período de 1905 a 1913 representou um salto quantitativo na capacidade produtiva, com São Paulo contornando a crise interna e externa das vésperas da Primeira Guerra Mundial, atendendo ao mercado periférico 
nacional. E a década de 1920, viria desembocar numa nova expansão da capacidade produtiva da indústria paulista, favorecida pelos lucros do período da guerra. Para Cano (1985, p. 64), “essa superinversão dos anos de 1920, resultando, mais tarde, em alto grau de capacidade ociosa, provocou um acirramento da luta intercapitalista interregional, de onde saiu vitoriosa a indústria paulista, que lançava, assim, bases mais sólidas para a definitiva conquista do mercado nacional. De pouco mais de $15 \%$ da produção industrial brasileira em 1907, São Paulo chegava, em 1929, com pouco menos de 40\%".

Essa posição de São Paulo no mercado nacional é examinada por Cano (1985) na crescente participação da produção para o mercado interno nas exportações totais paulistas. No período de 1900-1910, a produção exportada por São Paulo se destinava em $85 \%$ para o exterior e $15 \%$ para o mercado interno. Em 1920-1930, essa divisão percentual encontraria seu equilíbrio com metade sendo exportada e a outra consumida no país. $\mathrm{Na}$ década de 1960, a proporção para o mercado interno já estaria profundamente alterada, absorvendo 85\% das exportações. Para Cano (1985, p. 64), a contrapartida da periferia nacional seria a de modificar também sua estrutura comercial externa, ajustando-se "a uma função complementar à economia paulista”.

A crise de 1929 desarticularia o comércio exterior, com a restrição das importações. A periferia nacional passaria a importar manufaturados de São Paulo e lhe forneceria matérias-primas e alimentos. " $\mathrm{A}$ periferia, nada mais restava do que ajustar-se a uma função complementar da economia de São Paulo, embora mantendo ainda sua antiga dependência do exterior, através de suas exportações tradicionais" (Cano, 1985, p. 64).

O caso de Minas Gerais é visto por Cano (1985, pp. 59-62) como de integração às economias de São Paulo e Rio de Janeiro. Como a região fluminense, sua cafeicultura foi submetida ao capital mercantil carioca e comercialmente, ao desenvolver sua lavoura de alimentos, os laticínios e a pecuária, conseguiu se integrar melhor aos mercados de seus estados vizinhos. As exportações mineiras somavam-se à expansão imobiliária da construção de Belo Horizonte, que permitiram a criação de um sistema bancário embrionário próprio, os "famosos Bancos 'Mineiros". A crise cafeeira em Minas no final do século XIX só seria superada na década de 1920, sendo amenizada na economia mineira pela integração comercial com os outros estados na exportação de gêneros alimentícios e gado, mais tarde pelo extrativismo mineral fornecido às indústrias transformadoras do Rio de Janeiro e de São Paulo.

A participação dos estados na produção industrial brasileira apresentaria um decréscimo a partir de 1907, demonstrando a sua redução em relação ao crescimento paulista no mercado interno. Rio Grande do Sul passaria de 13,5\% em 1907 para 9,8\% em 1939. Pernambuco de 7,4\% declinaria para 4,8\% no mesmo período. A Bahia e a região Norte, respectivamente, de $3,4 \%$ e $4,3 \%$ para $1,4 \%$ e apenas $1,1 \%$. O Nordeste, como um todo, de 16,7\% para 10,4\%. São Paulo em 1907 abarcava $16 \%$ da produção industrial, saltaria para 31\% em 1919 e 45\% em 1939. Minas Gerais, graças a sua maior integração com a economia paulista, se beneficiou de seu crescimento, sendo um dos poucos que aumentou a sua participação na produção industrial no período, de 4,4\% em 1907, para 5,6\% em 1919 e 6,5\% em 1939. A cidade do Rio de Janeiro, que possuía o parque industrial mais diversificado do país, em 1907 liderava a produção industrial com $30 \%$, cairia sua participação para 21\% em 1919 e 17\% em 1939 (Cano, 1985, pp. 70-71).

Nessa perspectiva de Cano (1985) sobre a constituição do mercado nacional, a integração dos mercados regionais só aconteceria com a concorrência inter-regional encabeçada pelo setor industrial paulista. Esse fenômeno só se iniciaria na década de 1920 e se concretizaria após à crise de 1929. A argumentação acompanha a participação crescente de São Paulo na produção industrial brasileira. No entanto, os dados obtidos no levantamento de Lloyd (1913) nos permitem retroceder na integração dos mercados regionais a uma data anterior. Grande parte das empresas de maior relevo no panorama industrial do país já atuava fora de seus mercados locais e regionais antes da ascensão paulista, com relevo para o parque industrial do Rio de Janeiro, esquecido por Cano (1985).

$\mathrm{Na}$ realidade, essa concorrência foi vencida pela concentração financeira no Rio e São Paulo, onde o capital inicial das maiores indústrias não possuíam contendores em outros estados. A liderança de São Paulo no mercado interno só poderia se dar através dessa etapa que a antecede, de integração nacional, para que a concorrência se efetivasse em seu benefício e em detrimento das indústrias de menor capital dos outros estados. Essa etapa que se inicia ao final do século XIX, com a modificação da legislação sobre as sociedades anônimas, a reestruturação do setor bancário, o fim da escravidão e o Encilhamento, se aprofunda no início do século XX até às vésperas da Primeira Guerra Mundial. Os contornos que a 
concentração de capitais toma em São Paulo, com os recursos de seu veio agroexportador do café, possibilitou a arrancada paulista de seu parque industrial, aproveitando-se das restrições das importações para expandir suas mercadorias para outras regiões do país.

Pelas informações obtidas na publicação da Lloyd's, podemos notar que a interligação se fortaleceu entre as praças dos estados do Nordeste e Norte com as praças do Rio Grande do Sul, no início do século XX. Podemos quantificar essas informações utilizando as descrições dos destinos nacionais das vendas ou importações de mercadorias das empresas mercantis e fábricas dos estados dessas três regiões, como um exercício inicial. Nem sempre essas informações foram fornecidas pelas firmas.

O quadro apresentado precisa ser explicado em relação ao uso das informações do Lloyd's sobre 427 empresas fabris e comerciais de estados nordestinos e sulistas. A primeira observação é que a região Norte é citada de forma imprecisa, compreendendo o Nordeste e o Norte. Da mesma forma, o Sul aparece nas informações das empresas do Pará e Amazonas dessa maneira generalizante, englobando o Sudeste e o Sul. Como critérios para a quantificação de cada forma de atuação, consideramos que quando a descrição das vendas, da representação como agência de outras empresas ou a importação de mercadorias se referem a todo o país ou somente a região é indicada de forma ampla, mantivemos a literalidade dessas classificações dos mercados de atuação.
Quando a descrição nomeia o estado de destino ou importação de mercadorias, inserimos essa informação na região a que pertencem os estados. No caso de empresas que só descrevem suas vendas no próprio estado e não possuem outras vinculações de negócios fora dela, foram inseridas no campo restrito de só comerciar no estado de sua localização. Evidente que toda empresa atuava onde estava sediada, portanto, essa classificação só foi utilizada para as que não tinham outro vínculo qualquer com outros estados. É o exemplo de casas de importação e exportação do Amazonas, que importavam mercadorias da Europa ou Estados Unidos da América para vender aos seringueiros e exportavam borracha. As casas comerciais ou fábricas que produziam ou comerciavam apenas com o exterior foram alocadas no campo de sem informações, junto com as que não trazem informações sobre as vendas ou importações de mercadorias, por não nos permitir saber se atuavam também em alguma praça nacional, que é o objetivo que nos interessa.

Muitas empresas comerciais ou industriais atuavam em mais de uma praça do país. No computo do quadro não foram inseridas as firmas do setor de serviços, como bancos, seguradoras, empresas de construção, empresas de telefones, bondes etc. Nesse quadro, utilizamos apenas as informações que são encontradas para os estados do Norte, Nordeste e Sul. Alguns estados não possuem essas descrições de empresas como o Sergipe, cuja única fábrica citada tinha sede administrativa na Bahia e, por isso, foi incluída

Quadro 3 - Ramo de atuação e destinos nacionais das vendas ou importação de mercadorias por empresas mercantis e industriais

\begin{tabular}{|l|c|c|c|c|c|c|c|c|c|c|c|c|}
\hline \multicolumn{1}{|c|}{ Atuação/Estado } & BA & PE & RN & AL & MA & CE & RS & SC & PR & PA & AM & Total \\
\hline Indústria & 12 & 18 & 2 & 2 & 3 & 3 & 66 & 5 & 17 & 9 & 4 & 141 \\
\hline Comércio & 52 & 42 & 3 & 7 & 5 & 16 & 87 & 3 & 14 & 15 & 42 & 286 \\
\hline Norte & 7 & 18 & 2 & 3 & 2 & 3 & 14 & 0 & 4 & 11 & 9 & 73 \\
\hline Nordeste & 24 & 20 & 2 & 2 & 2 & 4 & 23 & 0 & 2 & 3 & 1 & 83 \\
\hline Sul & 8 & 20 & 1 & 6 & 1 & 3 & 12 & 4 & 0 & 4 & 4 & 63 \\
\hline Sudeste & 13 & 11 & 1 & 3 & 1 & 3 & 35 & 5 & 10 & 2 & 4 & 88 \\
\hline Centro-Oeste & 1 & 0 & 0 & 0 & 0 & 0 & 4 & 0 & 1 & 0 & 0 & 6 \\
\hline Só no Estado & 7 & 7 & 0 & 0 & 0 & 2 & 49 & 1 & 4 & 4 & 25 & 99 \\
\hline Em todo país & 14 & 9 & 0 & 1 & 2 & 0 & 35 & 1 & 4 & 0 & 2 & 68 \\
\hline S/informação & 19 & 9 & 0 & 2 & 3 & 6 & 23 & 0 & 12 & 6 & 4 & 84 \\
\hline Total de empresas & 64 & 60 & 5 & 9 & 8 & 19 & 153 & 8 & 31 & 24 & 46 & \\
\hline
\end{tabular}

Fonte: Elaboração própria a partir de Lloyd (1913). 
nesse Estado. Além do Estado de Sergipe, Piauí e Paraína também não possuem informações de empresas, bem como Goiás, Mato Grosso e Acre.

Pelos dados coletados expostos no quadro acima, podemos perceber que os vínculos comerciais antigos entre alguns estados foram mantidos, como o caso da rota de cabotagem que no século XIX fora realizada entre o açúcar ou fumo de Pernambuco ou da Bahia com o Rio de Janeiro e o Rio Grande do Sul.

No Rio Grande do Sul, os charutos fabricados na Bahia encontravam consumidores. A firma Oliveira, Coelho \& Cia. era agente revendedor das centenárias águas minerais Caxambu (MG) e dos charutos São Félix, da fábrica baiana de A. Suerdieck, fundada em 1892 e só fechada no ano de 2000. As vendas da Suerdieck já alcançavam todo o país, por meio de caixeirosviajantes ou agentes representantes, além das exportações para a Argentina, Alemanha e Inglaterra (Lloyd, 1913, pp. 883-884).

De forma inversa, os carregamentos de charque das estâncias gaúchas continuavam abastecendo o Rio de Janeiro e o Nordeste, agora pela navegação a vapor e várias casas atacadistas, especializada no comércio desse gênero básico da alimentação da época. Mas, novas mercadorias e mercados vinham a se somar nesse circuito mercante, ampliando-o e fortalecendo-o. Foi o caso da disseminação das fábricas de tecidos a partir do final do Oitocentos, que começaram a demandar o fornecimento nacional de algodão, geralmente obtido nos estados do Nordeste, diminuindo consideravelmente as importações de fios da Europa ou Estados Unidos, como comentamos. Em contrapartida, empresas sulistas exportavam grande quantidade de outra mercadoria para o mercado nacional: as madeiras para o Sudeste e para as fábricas moveleiras ou companhias de construção de todo o país, que encontravam larga atividade nas reformas das cidades, nas vias férreas, bondes, usinas e obras de saneamento.

Quanto aos novos mercados, podem ser vistos como no caso da fábrica Santo Onofre do empresário Justiniano Simões Lopes, dedicada ao charque frescal em lata, "artigo esse de grande consumo no extremo norte do Brasil e principalmente no Acre"(Lloyd, 1913, p. 844). As fábricas têxteis ou de sapatos do Rio Grande do Sul também encontravam escoamento nas praças nordestinas, por meio de inúmeras casas comerciais que adquiriam fazendas nos diversos portos do país. Algumas dessas casas também eram agentes de fábricas do Sudeste ou Sul, como diversos estabelecimentos baianos dedicados ao comércio atacadista de tecidos nacionais.

Era grande o número de atacadistas de tecidos nacionais na Bahia que, enviando seus viajantes, redistribuíam essas mercadorias por todo Nordeste e outros pontos do país, como o norte de Minas. A Moraes \& Cia., dava exclusividade ao comércio da manufatura de tecidos das fábricas baianas, além de grande volume de fazendas europeias. Suas vendas eram realizadas no Norte e no Sul (Lloyd, 1913, p. 887).

Com isso, podemos reparar que a integração nacional entre a produção têxtil e seu escoamento nacional já havia se estabelecido plenamente nesse início de década. A concorrência interestadual, portanto, remontaria com certeza aos fins do século XIX, momento em que a maioria das fábricas ou firmas comerciais historiadas pela publicação de Reginald Lloyd se estabelecem ou sofrem sua incorporação como sociedades anônimas por ações. Esse fato escapa da análise da historiografia em geral. Seja pela compreensão de que o mercado nacional só surgiria com o fim da escravidão ou pela atuação hegemônica do setor fabril paulista, capaz de romper com o isolamento dos mercados regionais na década de 1920 a 1930. Essas interpretações não aprofundaram suas proposições analíticas em dados do século XIX, sobre os fluxos de comércio entre as regiões brasileiras ou sobre as modificações urbanas que se processaram antes do final da escravidão, possibilitando uma ampliação do mercado consumidor nas principais cidades do país.

Mas o que podemos extrair desses dados da companhia Lloyd's? Uma primeira observação é que os circuitos mercantis mais conhecidos se mantiveram consolidados entre Nordeste-SudesteSul, a velha rota de cabotagem que os negociantes de grosso trato da praça carioca utilizavam para os carregamentos de carne seca das charqueadas gaúchas para a redistribuição para os atacadistas e varejistas na Corte. Traziam do Nordeste o açúcar e outros mantimentos e do Rio de Janeiro, chegava o café e, agora, diversos produtos industrializados. Mas a circulação de mercadorias havia se ampliado, com 68 empresas declarando que negociavam seus produtos em vários portos do país. Podemos notar que a região Centro-Oeste mostrava ainda uma baixa integração ao mercado nacional. Era uma região ainda pouco industrializada. O Centro-Oeste e o sul de Minas Gerais se interligariam à cafeicultura do Oeste Paulista, no final do século XIX, pela via férrea e áreas de navegação fluvial (Saes, Martins \& Gambi, 2016, Domingues Neto, 2009, Costa, 2017). O território do Acre também se ligava tenuamente à Belém do Pará ou Manaus, 
particularmente pelo comércio da borracha. O Rio Grande do Sul mostrava um bom desenvolvimento industrial em relação ao nordeste, embora $32 \%$ das empresas restringissem suas transações ao mercado gaúcho (Nogueiról, 2003, Graça Filho, 2002, , Lenharo, 1979). Os estados sulistas também revelam uma forte relação comercial com os países do Prata, no fornecimento de erva-mate, carnes, couros, línguas em conserva, fumo, madeiras, lã etc., em troca, importavam grandes quantidades de trigo argentino e secos e molhados das repúblicas do Prata. Esse relacionamento mercantil às vezes ultrapassava as fronteiras, com a criação de filiais na Argentina ou firmas argentinas criando empresas nos estados sulistas. Por exemplo, a firma de tecidos dos gaúchos Pedro e Carlos Bina, estava estabelecida em Buenos Aires havia mais de 60 anos. Importavam tecidos da Europa e Estados Unidos e os revendiam em todo interior do Rio Grande, por meio de 5 viajantes (Lloyd, 1913, p. 837). Da mesma forma, a grande casa importadora de ferragens e máquinas do porto-alegrense Arthur Bromberg, além de suas filiais espalhadas pelas principais praças gaúchas, estabelecera também casas no Rio de Janeiro, Montevidéu e Buenos Aires (Lloyd, 1913, p. 821). E, ao inverso, a firma portenha Freixas Urquijo \& Cia era proprietária do engenho de beneficiamento de erva mate em Curitiba, dirigido pelo exportador Nicolau Mäder, estabelecido em 1907. Movido a vapor, o engenho empregava 25 operários e exportava anualmente cerca de 3 mil toneladas de erva mate para à Argentina e Uruguai (Lloyd, 1913, p. 966).

Tanto as empresas do Rio Grande do Sul, quanto as da Bahia e de Belém, atuavam como revendedoras de produtos manufaturados para o mercado regional, composto pelos estados vizinhos. As firmas exportadoras e importadoras predominavam no grande comércio de Belém e Manaus, devido as exportações de borrachas, castanhas e produtos locais para a Europa e Estados Unidos. O Estado do Maranhão mostrava também uma permanência de sua vinculação comercial com os estados do Pará e Amazonas, embora as informações sejam escassas. As firmas comerciais maranhenses de importação e exportação, como a Fernandes Pinto \& Cia, a Cunha Santos \& Cia e Jorge \& Santos, remetiam cereais para o Pará e Manaus e exportavam a tapioca e couros para a Europa (Lloyd, 1913, p. 1.030).

Devemos ressaltar que o desenvolvimento das vias de comunicação, seja por companhias de navegação a vapor ou ferrovias com seus múltiplos ramais, permitiram a ligação entre diversos mercados locais ou regionais, facilitando a localização de empreendimentos no interior do país, como já relatamos no caso da Companhia Industrial São Joanense de tecidos, beneficiária de um ramal da E. F. Oeste de Minas.

A Estrada de Ferro Oeste de Minas alcançou a cidade de São João del Rei em 1891, ligando-a à Estrada de Ferro D. Pedro II (hoje, Estarda de Ferro Central do Brasil), com sede no Rio de Janeiro, possibilitando que a Cia. Sanjoanense colocasse seus produtos naquela praça com maior facilidade.

Quase sempre as fábricas localizadas no interior escoavam sua produção ou obtinha a matéria prima por meio de seus armazéns estabelecidos às margens de vias fluviais ou de ramais de estradas de ferro. Era a outra face da construção do mercado nacional nos primórdios da disseminação das sociedades anônimas.

\section{Conclusões Preliminares}

Ao longo desse texto, reafirmamos a diferença conceitual entre mercado interno e mercado nacional, compreendendo esse último como uma construção histórica de novo tipo, um mercado interno interligado, próprio do avanço da divisão do trabalho na produção de mercadorias.

Também, por meio das informações prestadas à empresa britânica de seguros marítimos Lloyd's constatamos que os mercados regionais do país já estavam interligados no início da segunda década do século XX. Nesse particular, considerando que a grande maioria das companhias descritas tiveram suas incorporações como sociedades anônimas por ações ao final do século XIX, elevando consideravelmente seus capitais, o que nos indica a possibilidade dessa construção do mercado nacional ter se efetuado naquele contexto histórico do fim das restrições à formação de empresas por capital aberto, assunto que pretendemos explorar na continuidade dessa pesquisa.

A pesquisa sobre a Cia. Indústrial $\mathrm{S}$. Joanense, nos levou a perceber as disparidades regionais e as dificuldades de concorrência com as grandes plantas fabris do Rio e de São Paulo, também nos apontou as modificações surgidas para garantir a sua existência secular, com a maior integração ao mercado nacional, buscando a matéria-prima em regiões distantes do país, abandonando as importações de fios estrangeiros. Estratégia que passou a ser comum na indústria têxtil nacional no século XX.

Quanto à integração dos mercados regionais, também é preciso assinalar que cabe uma 
revisão historiográfica em relação à compreensão de que esse processo teria se realizado com a hegemonia industrial de São Paulo e seu complexo cafeeiro, a partir dos anos 20 e 30 do século passado. Essa perspectiva de análise se encontra nas obras consagradas de Cano (1985) e em Gorender (1981), sobre a burguesia brasileira. Nelas, a superioridade industrial de São Paulo submeteria as demais regiões à sua concorrência e integração, com a demanda crescente por matériaprima, rompendo com o isolamento dos mercados regionais que favoreciam a existência das empresas de vendas limitadas ao próprio estado ou região. Em nossa análise, essa concorrência se impôs antes desse momento da hegemonia industrial paulista, que sucedeu à carioca no setor fabril. As causas que justificariam os desequilíbrios regionais no setor industrial brasileiro teriam operado na sua constituição ao final do século, processo já marcado pela acumulação mercantil regionalizada e acontecida ao longo do século XIX, com o declínio açucareiro nordestino e o domínio do tráfico negreiro pela Corte e das exportações da cafeicultura do Vale do Paraíba. Desse modo, a hegemonia posterior de São Paulo só veio a reforçar os desequilíbrios regionais, mantendo a supremacia do Sudeste na reprodução ampliada do capitalismo brasileiro.

Podemos considerar que essas disparidades regionais foram um freio para o desenvolvimento da Cia. Industrial S. Joanense, que não pode contar com o mesmo nível de acumulação de capitais que favorecera os parques industriais do Rio de Janeiro e de São Paulo, animados pela forte concentração regional dos investimentos em ações e dos créditos bancários.

\section{Referências bibliográficas}

Braga, T. (1913). Album da Cidadde de S. João D 'ElRei. Rio de Janeiro: Typ. Lithographia Pimenta de Mello \& Cia.

Cano, W. (1985). Desequilíbrios regionais e concentração industrial no Brasil, 1930-1970. São Paulo: Global.

Cerutti, M. (1987). El gran norte oriental y la formación del mercado nacional en México a finales del siglo XIX. Siglo XIX Revista de Historia, II (4), 53-80. Monterrey, México.

Companhia Têxtil São Joanense. (1893). Estatutos da Companbia Industrial S. Joannense. São João del Rei: Typ. da Gazeta Mineira.
Companhia Têxtil São Joanense. (1991). Folhetim comemorativo dos 100 anos da Companbia Têxtil São Joanense "Tecendo a bistória da Companbia Têxtil São Joanense, 1891-1991”, São João del Rei.

Costa, R. G. (2017). Transformações no mercado interno paulista (séc. XIX). Jundiaí: Paco Editorial.

Domingues Neto, H. (2009). Navegando o MogiGuacu. A agroexportação cafeeira no Oeste Paulista e a formaça de um mercado regional interno regional (1883-1903). São Paulo: Ed. Unesp.

Gorender, J. (1981). A burguesia brasileira. São Paulo: Brasiliense.

Graça Filho, A. A. (2002). A Princesa do Oeste e o mito da decadência de Minas Gerais. São João del Rei (1831-1888). São Paulo: Annablume.

Lenharo, A. (1979). As tropas da moderacão: o abastecimento da Corte na formação política do Brasil, 1808-1842. São Paulo: Ed. Símbolo.

Libby, D. C. (1996). Protoindustrialização em uma sociedade escravista: o caso de Minas Gerais. In T. Szmrecsányi \& J. R. A. Lapa (Orgs.). História econômica da Independência e do Império ( $3^{a}$ ed., pp. 274-275). São Paulo: Hucitec/Fapesp/ABPHE.

Lloyd, R. (1913). Impressões do Brazil no Seculo Vinte. Sua Historia, seo povo, commercio, industrias e recursos. Londres: Lloyd's Greater Britain Publishing Cia. Ltd.

Nogueiról, L. P. F. (2003). Sabará e Porto Alegre na formacão do mercado nacional no século XIX. (Tese de Doutorado em Economia). Campinas (SP): Unicamp/Instituto de economia.

Paula, J. A. (2002). O mercado e o mercado interno no Brasil: conceito e história. Revista de História Econômica \& História de Empresas, 1 (2002), 7-39. São Paulo: Hucitec/ABPHE. Recuperado em 6 agosto, 2019, de www.abphe.org.br/revista/index.php/rab phe/article/view/126/158

Rangel, I. (1957). Dualidade básica da economia brasileira. Rio de Janeiro: MEC/Instituto Superior de Estudos Brasileiros.

Saes, A., Martins, M. L., \& Gambi, T. (2016). Sul de Minas em urbanização. São Paulo: Alameda.

Sereni, E. (1980). Capitalismo y mercado nacional. Barcelona: Editorial Critica.

\section{Notas}

i Companhia Têxtil São Joanense. (1991). Folbetim comemorativo dos 100 anos da Companbia Têxtil São Joanense "Tecendo a história da Companbia Têxtil São 
Joanense, 1891-1991”, São João del Rei. Companhia Têxtil São Joanense (1893). Estatutos da Companbia Industrial S. Joannense. São João del Rei: Typ. da Gazeta Mineira.

ii A economia de abastecimento na região da Comarca do Rio das Mortes foi fundamental para manter a sua dinâmica econômica após a crise da mineração. A pecuária, a suinocultura e seus derivados foram as principais mercadorias de Minas para os mercados das capitanias/províncias limítrofes, particularmente o mercado do Rio de Janeiro (Lenharo, 1979; Graça Filho, 2002).

iii Os valores utilizados nesse artigo estarão em moeda da época, cuja unidade era o real e seu plural, o réis. A utilização dessa unidade monetária perdurou por todo século XIX a no XX, até 1942, quando se adotou o cruzeiro como novo padrão de moeda.

iv $\mathrm{O}$ Encilhamento foi o apelido dado à política financeira do ministro da Fazenda, Rui Barbosa, no início do governo republicano no Brasil, em 1891. Essa política financiou a criação de novas indústrias e sociedades anônimas por meio de títulos da dívida pública, gerando grande especulação das ações na Bolsa de Valores. Muitas dessas empresas eram fictícias e essa grande especulação gerou inflação e falências posteriormente.

v Companhia Têxtil São Joanense. (1893). Estatutos da Companbia Industrial S. Joannense. São João del Rei: Typ. da Gazeta Mineira.

vi Podemos citar como exemplos Rangel (1957) e Paula (2002).

vii Ver Nogueiról (2003). 